\title{
OPEN DATA AND COMPETITION LAW: SOME ISSUES REGARDING ACCESS AND PRICING OF RAW DATA ${ }^{1}$
}

\author{
by \\ BJÖRN LUNDQVIST*, YLVA FORSBERG*, \\ MARC DE VRIES $^{* * *}$, MARIATERESA MAGGIOLINO**** $^{* *}$
}

Public sector information (PSI) is a very valuable resource that, back in 2003, the EU parliament and council decided to appraise by incentivizing its re-use via a dedicated Directive. In 2013, the directive was revised to further promote the development of a single European market for information goods and services. On the bases of the European and national case law, this article investigates the main competitive issues that this EU law about PSI triggers.

\section{KEY WORDS}

Public Sector Information, Open Data, Re-use, Competition Law

\section{INTRODUCTION}

The efforts of the European Commission are paying off: increasingly governments all over Europe are opening up their data, often without charging for the re-use. This in perfect sync with the spirit and mission of the 2003 and, in particular, 2013 PSI Directives, which both advocate free availability of PSI. In fact, Article 6 of the PSI Directive imposes, as

1 This article stems from the research conducted within the thematic network, LAPSI 2.0 $<$ http://www.lapsi-project.eu/>

Bjorn.Lundqvist@juridicum.su.se, Associate Professor Copenhagen Business School, and Senior Lecturer, Juridicum Stockholm University.

* Senior Associate, Roschier Advokatbyrå AB.

*** Partner, Citadel Consulting.

**** Assistant Professor of Commercial Law at Bocconi University, Department of Legal Studies, Milan and Visiting Professor at Fordham School of Law. 
the general rule, marginal cost, as the ceiling, for what fees may be obtained by the Public Sector Bodies (PSBs).

Interestingly, lately incumbent market players have been submitting claims that this change of policy is in fact illicit, harming their commercial interests. They argue that by opening up their PSI these governments are conducting unfair competition practices, or at least inflicting damage.

This claim merits deeper consideration: if these incumbent players are right, this could impact adoption of Open Data policies by governments throughout Europe and in fact frustrate the sound application of the PSI Directive.

The paper will initially discuss the PSI Directives and the interface between the PSI Directives and Competition law, so to establish what is encompassed by the directives and what should be judge under competition law, respectively. Thereafter some cases from different Member States will be reviewed and analysed. This is to show that there might be some disfunctionality in reference to the interplay between the legal systems. We therefore conclude with a policy suggestion that the competition authorities should try to establish when competition law is applicable to PSBs, generally, i.e. when an alleged commercial practise also is the PSB's public task.

\section{BACKGROUND}

\subsection{PUBLIC TASKS AND COMMERCIAL ACTIVITIES UNDER THE PSI DIRECTIVE}

The starting point of the PSI Directive is the notion that PSBs have been established to perform one or more tasks: the public tasks. This is the raison d'être for the public sector. These tasks are normally laid down in formal laws (like the Law on the Cadastre, or the Law on the National Meteorological Institute) or Governmental Instructions. In the process of performing those tasks - the public tasks - the PSBs accordingly "collect, produce, reproduce, and disseminate documents." This is the PSI the Directive wants to catch: it wants to apply to the PSI that is produced "anyway", whereby the public task is in fact the demarcation line for application. Accordingly, Art 1(2)(a) says: 
"This Directive shall not apply to:

(a) documents the supply of which is an activity falling outside the scope of the public task of the public sector bodies concerned as defined by law or by other binding rules in the Member State, or in the absence of such rules as defined in line with common administrative practice in the Member State in question."

The relationship between public tasks and other (commercial) activities is naturally linked to the perception of the role of government in society. The principles and practices of government differ significantly between the Member States. In some Member States, the government is expected to stay away from the market, while in others it is supposed to take part in it, in order to gather at least part of its funding. ${ }^{2}$

The now amended Recital 9 of the preamble of the PSI Directive explains that activities falling outside the public task typically will include supply of documents that are produced and charged for exclusively on a commercial basis and in competition with others in the market. This provides some guidance on the limits of the public task and provides a number of features to consider in the assessment of the scope of the public task. The guidance sets out an example of supply, which would typically fall outside the public task. Obviously, other indicators for the character of a PSB's activities may be found in national legislation and practices. ${ }^{3}$

The wording of the Directive makes clear that public tasks, in the view of the Directive, can be of both commercial and non-commercial nature. For instance Art. 10 (2), which deals with the situation when a commercial branch of a PSB re-uses the PSB's own PSI, sets out two requirements for applicability: commercial activity and outside public task. If the two terms were to have the same meaning, there would be a tautology. Hence, the Directive leaves room for a discrepancy between commercial and noncommercial public tasks (and non-public tasks), which justifies the need for Art. 10 (2). ${ }^{4}$

The Directive does not seek to harmonize the scope of the public tasks assigned by Member States ${ }^{5}$, in particular because this is a national prerogative. Therefore, the answer to the question whether or not

See, Janssen, 2005, 12.

See, Janssen, 2011.

See, Lundqvist, de Vries, Linklater and Malmgren, 2011, 46.

5 See Proposal for the PSI Directive, op. cit., 8. 
commercial activities can fall within the scope of a PSB's public task will depend on the way the public sector is organized and controlled in the respective Member States. The PSI Directive leaves room for different perceptions of public task. In some countries, the PSI Directive will cover commercial activities of PSBs and in some countries not, due to different roles of the respective governments. The important thing when implementing the Directive is to design the national implementing regulation in accordance with the existing form of governance. ${ }^{6}$

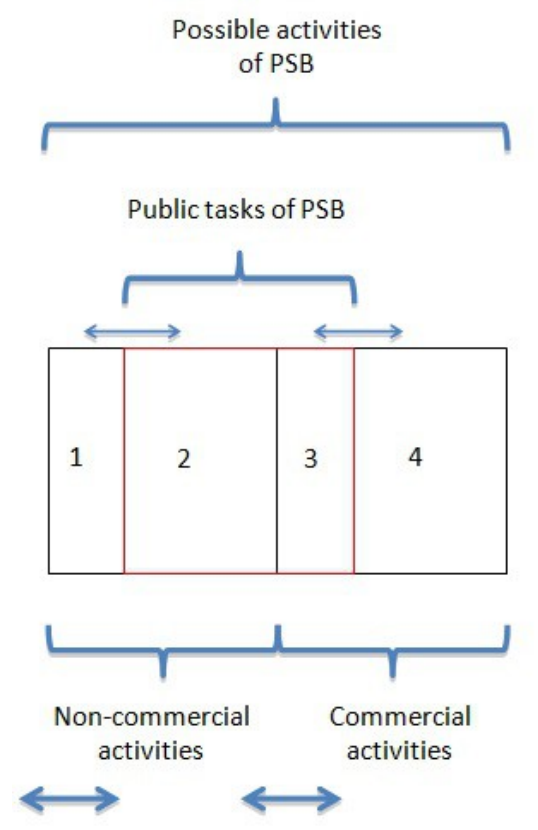

The figure above illustrates how possible activities of a PSB can be divided into commercial and non-commercial activities and how the public task area, represented by the red square, may cover parts of different sizes of these two kinds of activities. Four combinations of activities are possible and the size of each part depends on the governmental regime of which the PSB is part: (1) non-public non-commercial activities; (2) public noncommercial activities; (3) non-public commercial activities, and; (4) nonpublic commercial activities. The practical cases of (1) may be rare or even only existing in theory, whereas the distinction between the three other fields ((2)-(4)) are of great and practical importance for understanding

\footnotetext{
6 Compare Jansen, 2005, 12-13.
} 
the scope of the PSI Directive and for assessing the different national implementations.

\subsection{RE-USE}

Art. 2 (4) of the PSI Directive provides that:

"'Re-use' means the use by persons or legal entities of documents held by public sector bodies, for commercial or non-commercial purposes other than the initial purpose within the public task for which the documents were produced. Exchange of documents between public sector bodies purely in pursuit of their public tasks does not constitute re-use."

Here, the term public task shows up for the second time in the Directive. Interestingly, the definition of re-use requires the original PSI to be produced within the public task, whereas Art. 1 (2) (a), as stated above, requires the supply of PSI to be a public task. In the light of recital 9 of the preamble of the Directive, the word produced must be interpreted as also including at least the collection and reproduction of documents. Use of such documents for other purposes than the initial purpose for why the data was collected or produced constitutes a re-use. The PSI Directive uses a broad definition of re-use encompassing basically any following activity with the data, as long as the purpose of this re-use is different from the initial purpose. ${ }^{7}$

The last sentence of Art. 2 (4) makes clear that the exchange of documents between different PSBs purely in pursuit of their public tasks does not constitute re-use. This appears like a superfluous sentence, since it seems clear from the first sentence that the situation described does not constitute re-use. The identity of the re-user is irrelevant, but the second use must occur outside a public task. Second use of PSI by the same PSB (i.e. the original PSI holder) within the scope of its public tasks ought not to constitute re-use either, though this is a question of interpretation.

\subsubsection{RE-USE BY PSB}

As has already been suggested, re-use does not necessarily need to be performed by private sector parties. PSBs can re-use themselves and they can re-use their own PSI. This happens when PSBs use the same documents in activities within their public tasks as in activities outside their public

\footnotetext{
7 See, Lundqvist, de Vries, Linklater and Malmgren, 2011, 34.
} 
tasks. Re-use by PSBs often involve adding value to the PSI that the PSBs have collected for certain users, or developing added-value products for a comprehensive consumer market, that are constructed from the original data gathered within the exercise of the PSBs' public tasks. ${ }^{8}$ Examples of such commercial products are custom-made weather forecasts constructed from meteorological information, or market surveys based on statistical data. The original information collected with public capital and within the exercise of the public task should be available for re-use, in contrast to the commercial information products and services resulting from that information. ${ }^{9}$

A PSB re-using its own PSI commercially is subject to Art. 10 (2) of the PSI Directive and must consequently make sure not to discriminate against other re-users in its charging policy or re-use conditions. ${ }^{10}$ Art. 10 (2) of the PSI Directive states:

"If documents are re-used by a public sector body as input for its commercial activities which fall outside the scope of its public tasks, the same charges and other conditions shall apply to the supply of the documents for those activities as apply to other users."

Thus, a PSB must use the same terms and conditions on itself as on third parties when using PSI documents as an input to: (i) commercial activities that (ii) fall outside the scope of public task. Thus, the wording public task shows up for the third time in the PSI Directive, but this time together with the term commercial activity. Important to notice is that for Art. 10 (2) purposes, it is the PSB's re-use activity that needs to fall outside the public task for the non-discrimination clause to apply, and not its initial supply of the PSI in question. ${ }^{11}$

Even though, as concluded above, non-public non-commercial activities of a PSB ((1)-cases in the figure above) must be rare, one can ask what happens if a PSB re-uses its own PSI for non-commercial purposes outside its public tasks. Then Art. 10 (2) is not applicable, but the rest of the provisions in the PSI Directive might apply. Art. 10 (1) states that any applicable conditions for the re-use of documents shall be non-

Compare Proposal for the PSI Directive, 8 and Lundqvist, de Vries, Linklater and Malmgren, 2011, 34.

9 Proposal for the PSI Directive, 7-8.

${ }_{10}$ See, Lundqvist, de Vries, Linklater and Malmgren, 2011, 34.

11 Ibidem, 37-38. 
discriminatory for comparable categories of re-use. Thus, this nondiscrimination provision applies when a PSB re-uses PSI for noncommercial purposes, but it is less strict than the absolute discrimination prohibition in Art. 10 (2), as it allows different conditions for different categories of re-use.

The structure of the PSI Directive is knotty whereby the term public task appears three times. First, the genesis of the PSI must have occurred within the public task for the PSI Directive to apply. Secondly, the supply of the PSI must be an activity falling within the public task of the PSB holding the document. At the same time as these public task requirements must be met in order for the Directive to apply, the public task also functions as a shield against the application of the Directive. As long as the PSI does not leave the public task-area, the Directive does not apply. First when the PSI leaves the safe harbor of public task and reaches actors outside that area, does the PSI Directive kick in. This might also explain why Art. 1 (2) (b) utilizes the term supply. The supply of PSI is an out-reaching activity, which is a necessary element for this transportation of PSI, from public task to non-public task, to take place.

The figure below illustrates when the PSI Directive becomes applicable in terms of public task, commercial activity and re-use. The red arrows indicate that the PSI Directive applies to the transfer of PSI, and green arrows indicate that the PSI Directive is not applicable. Thus, the PSI first needs to have its origin in the red square (the public task area) for the Directive to apply (all red arrows start within the red square). But the PSI also needs to leave that area for the Directive to apply (all red arrows end outside the red square). When the PSI leaves the public task area and reaches external actors, the Directive applies. When it leaves the public task area but stays within the PSB, and is an input for the PSB's commercial activities, Art. 10 (2) becomes applicable. This means that the external actors receive the same position in relation to the public task part of the PSB as the commercial branch of the PSB does. The external actors have the right to receive the PSI on the same terms and conditions as the commercial branch of the PSB. If the PSI documents are used as an in input to commercial activities falling inside its public task, Art. 10 (2) is not applicable. If the PSI leaves the public task area and stays within the PSB but as an input to noncommercial activities, the Directive applies, as the re-use requirement is still met, but Art. 10 (2) does not apply. 
Activities of a PSB

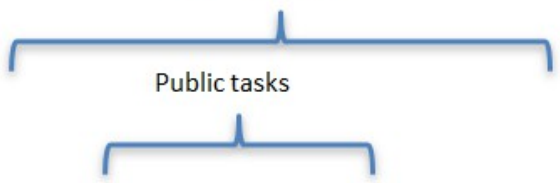

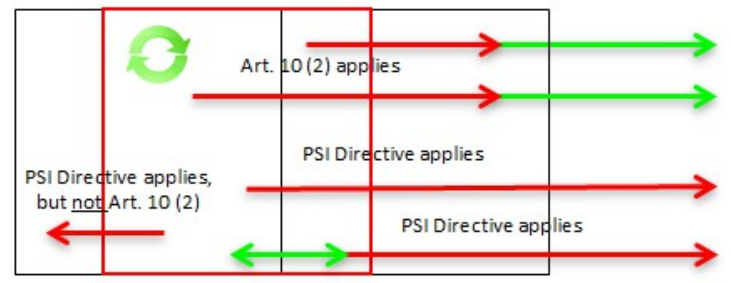

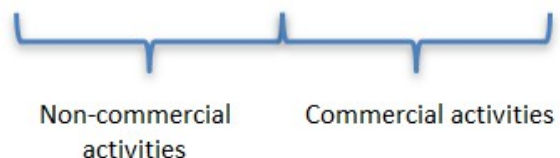

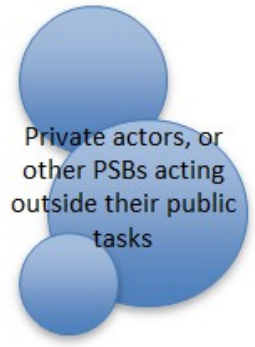

This way of defining the scope of the Directive is to some extent in line with general competition law. It is only when the PSI leaves the public taskarea that PSBs are acting as (potential) competitors on a (hypothetical) market. A PSB re-using PSI outside the public task, which by the way could be a pleonasm considering the definition of re-use, should not be in any superior position compared to a third (market) party looking to re-use the same PSI. ${ }^{12}$ Accordingly, the PSI Directive creates a level playing field between PSBs and other re-users: as soon as a PSB leaves the public task territory, it loses its "competition (law) principles immunity" and the absolute discrimination prohibition in Art. 10 (2) becomes applicable. ${ }^{13}$ Again, though, this transit between the PSI Directive and general competition law is a bit more complex, as the different terms used to define the scope of the PSI Directive and to define the scopes of other competition provisions create an overlap between the legal frameworks, whereby there is a possibility for situations to arise where both the PSI Directive and competition provision apply and where there may be incidents of disharmony.

Under the Open data initiative, increasingly governments all over Europe are opening up their data, often without charging for the re-use. It is

\footnotetext{
12 See, Lundqvist, de Vries, Linklater and Malmgren, 2011, 34-35.

13 Ibidem.
} 
in perfect sync with the 2003 and, in particular, 2013 PSI Directives, which both advocate free availability of PSI. In fact, Article 6 of the PSI Directive stipulates as a general rule that "[w]here charges are made for the re-use of documents, those charges shall be limited to the marginal costs incurred for their reproduction, provision and dissemination". Nonetheless, an underlying idea of competition law is that transactions take place for remuneration reflecting market price. When the PSBs give access to PSI without charges both on the wholesale level and in the end-user market the principles of competition law and the PSI Directive may not correspond or even be contrary to each other. However, it depends in part on the definition of public (commercial) task and the size of "the public power and thereto connected conduct exemption" under Competition law. In part, it also depends on what weight you put to the argument: "we can provide this kind of service on a commercial basis. Hence, the state should not make such services a public task and provide the same service to citizens for free." Perhaps, it is actually creates an incentive to dynamically compete. Thus, the PSI Directive does not provide any basis for arguing that it aims at preventing PSBs from providing such services for free. Although the policy objective of the directive is to create markets for commercial added-value information markets that build on PSI re-use, the other objective is to make PSI available to citizens. It is important that open data policy does not exclude commercial re-users from the market, while it also facilitates a dynamic incentive to enrich and improve re-users services. Even more importantly, private re-users can aggregate data from different sources which is more difficult for PSB. In sum, open data policies put economic pressure on commercial re-users, but such pressure also create incentives for enhancing the quality of added-value services of commercial re-users.

This disharmony will be examined more fully below.

Again it becomes clear that the PSI Directive raises questions concerning the position of PSBs on the market and in society. If a PSB offers commercial information products on the market, the basic data it used for the product has to be available to the private sector on the same conditions as the PSB obtained them. Of course, this will be quite a challenge in practice, as the PSB will have to charge itself for documents that were already in its possession for the performance of its public task. To uphold this, a separation between the public tasks and the commercial activities of 
the PSBs is necessary. ${ }^{14}$ It is easily conceivable for a PSB to apply the same conditions on other PSBs as on private actors. But it will be quite a challenge to ensure that the PSB imposes the same conditions on itself as on any other body requesting the same documents, even when no actual transfer of the data is taking place. $^{15}$

\section{THE PSI DIRECTIVE IN RELATION TO COMPETITION}

\section{LAW $^{16}$}

\subsection{EU COMPETITION LAW}

The PSI Directive acts and EU competition law are two separate regimes. It should, thus, be the starting point when handling an issue of re-use of PSI held and supplied by a PSB. Both when having found that the PSI Directive applies and when having found that it does not apply, one has to go on to the competition provisions in TFEU in order to find out in which way general competition law possibly complements or extends the provisions (or lack thereof) in the PSI Directive. The correlation between the different terms that govern applicability of general EU competition law and the PSI Directive may be illustrated as in the simplified figure below.

SGEIs are always public tasks and can be conducted by undertakings. SGEIs may under certain circumstances be excluded from the applicability of the TFEU competition provisions (cf. Art 106(2) TFEU), and from the scope of the PSI Directive. ${ }^{17,18}$ The exercise of official authority always takes place within a public task and excludes the entity in that case from being regarded as an undertaking. Of course, more requirements need to be fulfilled for the respective set of rules to apply (like the absence of applicable exemptions, provided for in Art 1(2) (b)-(f)), but the figure gives an overview of how the terms decisive for the first questions of applicability relate to one another.

The statements above are without controversy. However, the overlap between the terms public task and undertaking is more in dispute.

14 Ibidem, 42-45.

15 Compare Correira, 2005.

16 For a very in-depth analysis of the interface between the PSI Directive and EU Competition law in general, and the Compass case in specific, see Drexl, 2015.

17 In accordance with Art. 106(2) TFEU, SGEI are exempted if the application of competition provisions on such conduct would obstruct the performance of the particular tasks assigned to the undertaking.

18 However, Art. 11 (2) of the PSI Directive states that where an exclusive right is necessary for the provision of a service in the public interest might be permitted. 
The CJEU recently implicitly discussed this interface in the Compass case ${ }^{19}$. The Compass case concerned the legal issue of whether the refusal to supply doctrine, under the abuse of dominance rule, may be applicable when the Republic Österreich (Austria) refused to give access to the digitalised Austrian Company Register to the limited company Compass-Databank $\mathrm{GmbH}$ (Compass) so to enable it to sell access to or information provided in the Austrian Company Register.

Compass would have sold access to the company register to customers on the same or at least on a neighbouring "market" as the private agencies assigned by Austria to provide access to this register. The CJEU found that Compass would not be able to utilize the refusal to license of supply doctrine because Austria when making the Austrian Company Register available to the public was conducting an inseparable activity or service from the exercises of public power of collecting the data for the same register. Thus, Austria did not function as an undertaking under EU competition law. ${ }^{20}$

The Austrian court did not ask about the PSI Directive, ${ }^{21}$ and the CJEU did not discuss the Directive in any length. CJEU stated that the PSI Directive in [the old] recital 9 states that the directive does not contain any obligation to authorise re-utilisation of documents. Moreover, the Austrian implementation of the PSI Directive explicitly exempted the Company register from its application. ${ }^{22}$ AG Jääskinen stated that the PSI Directive maystill be used for inspiration and guidance. ${ }^{23}$

Both the statement by the CJEU and the AG's justification for not using the PSI Directive seem somewhat odd. ${ }^{24}$ Indeed, it is unfortunate that

19 Case C-138/11 Compass-databank GmbH v. Republik Österreich, Opinion of Advocate General Jääskinen, 26 April 2012.For further discussions regarding the Compass-case, please see Lundqvist, 2014.

20 Ibidem.

${ }^{21}$ It seems like the court already had arrived to the conclusion that the Austrian PSI Act was not applicable. See Case C-138/11 Compass-databank GmbH v. Republik Österreich, Opinion of Advocate General Jääskinen, paras. 21 and 22.

22 Case C-138/11 Compass-databank GmbH v. RepublikÖsterreich, 12 July 2012, not yet reported, para. 50. See also Case C-138/11 Compass-databank GmbH v. Republik Österreich, Opinion of Advocate General Jääskinen, paras. 21 and 22.

23 Implicitly Jääskinen found that the PSB in this case had produced, reproduced and disseminated through the agencies the information in order to fulfil its public task. Hence, the PSI regulation could not be applicable since the there was no re-use, only use of the Company register. Case C-138/11 Compass-databank GmbH v. Republik Österreich, Opinion of Advocate General Jääskinen, paras. 36 et seq. See also Lundqvist, IIC, Op. cit. 
the Austrian court did not explicitly ask about the application of the PSI Directive. $^{25}$

Moreover, the CJEU in this case seems almost to have equated public task under the PSI Directive with non-economic activity under the notion of "undertaking" in competition law. According to CJEU, data collection activity in relation to undertakings, on the basis of a statutory obligation on those undertakings to disclose the data and powers of enforcement related thereto, falls within the exercise of public powers. ${ }^{26}$ As a result, such an activity is not an economic activity. Equally, an activity consisting in the maintenance and making available to the public of the data thus collected, whether by a simple search or by means of the supply of print-outs, in accordance with the applicable national legislation, also does not constitute an economic activity, since the maintenance of a database containing such data and making that data available to the public are activities which cannot be separated from the activity of collection of the data. ${ }^{27}$

With regard to the fact that the making available to interested persons of the data in such a database is remunerated, the CJEU noted that, in conformity with the case-law, to the extent that the fees or payments due for the making available to the public of such information are not laid down directly or indirectly by the entity concerned but are provided for by law, the charging of such remuneration can be regarded as inseparable from that making available of data. Thus, the charging by Austria of fees or payments due for the making available to the public of that information cannot

\footnotetext{
24 As discussed by Lundqvist, it is true that the PSI Directive does not oblige the authorisation of re-use according to [the old] recital 9, but that can only be understood that the Member State or the relevant PSB has a prerogative under the directive to re-use or not to re-use the PSI. If it does not re-use PSI, there is no duty under the PSI Directive to re-use. Nonetheless, has the PSB indeed started to re-use the PSI, i.e. use it outside the original public task for what it was produced or supplied for, the PSB is, on the contrary, obliged under the PSI Directive to give access to the PSI. It is the only plausible interpretation of recital 9, Arts. 1, 10(2), and 11 of the PSI Directive. In other words, if the transfer of PSI to the agencies from the Austrian State in this case could be considered a re-use, the PSI Directive should have been applicable. Now, it may be questioned whether a Member State, in accordance with Compass may exempt certain PSI, e.g. the Company register, from the national PSI legislation altogether.

It seems like the Austrian court already had arrived to the conclusion that the Austrian PSI Act was not applicable, see Case C-138/11 Compass-databank GmbH v. Republik Österreich, Opinion of Advocate General Jääskinen, paras. 21 and 22. Nonetheless, the explicit Austrian exemption of the Company register from the national implementation of the PSI Directive seems questionable. Lundqvist, IIC, Op. cit.

26 Drexl, 2015.

27 Case C-138/11 Compass-databank GmbH v. Republik Österreich 12 July 2012, not yet reported.,paras. 41 et seq.
} 
change the legal classification of that activity, meaning that it does not constitute an economic activity.

Some commentators find the outcome in Compass unfortunate. Firstly, it is unfortunate because thereby Competition law will not apply to a lot of the activities conducted by PSB, even though these activities presumably would affect competition on relevant markets.

Likewise the PSI regulation will perhaps not be applicable either given the definition of "public task". The definition of public task under the PSI Directive could be more narrow then "the public power and thereto connected conduct exemption" under Compass since the public tasks should under the PSI Directive at least be defined in the regulation to the PSB. However, since "public task" is the prerogative of the Member States in the PSI Directive, the Member States can, of course, increase the notion pf public task by including all sort of conducts in the regulation of the PSBs. The result of this would be that conducts that are both public tasks and economic activities would not be encompassed by either legal systems.

Secondly, it is moreover unfortunate because the activities conducted by PSBs which would be encompassed by competition law would probably also be addressed by the PSI Directive. A PSB acting in this area would seldom benefit from the application of either competition law or the PSI regulation, but when one is applicable the other would presumably also in many cases be applicable. Thus, the spheres in the graph above, representing public task (a PSI regulation term) and exercise of official authority and thereto connected activities (a competition law notion), respectively, would often cover the same forms of conduct.

\section{RELEVANT CASE LAW}

\subsection{INTRODUCTION}

Below, certain cases dealing with the interface between public tack and commercial activity, especially when PSB engages or enters established market, where PSI is traded, with free access to the PSI databases and discussed. The cases are reviewed to give examples where the underlying principles under the PSI Directive and Competition law are perhaps not in congruence. 


\subsection{DUTCH POSTAL CODES CASE ${ }^{28}$}

The Dutch government has been working on a system of authentic datasets (the so called basisregistraties) for a number of years. One of these authentic datasets is the BAG, holding addresses and buildings (Basisregistraties Adressen en Gebouwen). The data held in this registry were already available for re-use (including commercial use), except from the postcodes. From 1 February 2012 onwards, the postcodes will also be available for any type of use. PostNL, the holder of a postcode database, tried to prevent this in court, but the court decided that the postcodes should also be made available for re-use. This considerably increases the value of the BAG for reuse.

The authentic dataset of addresses and buildings (BAG) is maintained by the Dutch Cadastre. It holds the complete, updated and uniform list of addresses in the Netherlands, including the coordinates and information on the purpose, surface area and date of construction of the buildings. Every building and address has a unique identifier. The BAG is open for reuse by third parties, except for the postcodes. Decades ago, the system of the postcodes was set up by the PTT, the (at that time) state owned Postal Service. However, in the 1980s, this service was privatised and now the postcodes are held by a separate public company, PostNL. A Covenant between PostNL and the Dutch government determined that the postcodes could be provided by the government to third parties, but that the postcodes could not be used or disseminated for commercial purposes.

The policy of the Dutch government is that PSI should be made available in an easy and cheap manner to citizens and companies, whatever their intended use of the data might be. In order to include the BAG in this policy, the government proposed a change to the Covenant with PostNL in 2010, in order to allow the dissemination of the postcode database for commercial use. After refusing this change in April 2010, PostNL in December demanded an annual fee of 750.000 euro for the use of the postcode data within the BAG. The government did not accept this fee, and terminated the Covenant in January 2011 with a term of notice until 1 February 2012.

28 Case identifier: Koninklijke Post NLB.V. and Cendrid Dataconsulting B.V. versus the State of the Netherlands (Ministry of Infrastructure and Environment), Date: 21 December 2011, Court decision: http://zoeken.rechtspraak.nl/detailpage.aspx?ljn=BU9147 
PostNL started a procedure before the court of The Hague, together with Cendris B.V., a private company licensed by PostNL to commercially re-use the postcode database. PostNL demanded the State to be disallowed to disseminate the postcodes in bulk to third parties via the BAG.

First, PostNL claimed that the government had infringed its database rights, but the court found no infringement, because the government showed that it obtained the postcodes from the local authorities (who get the postcodes from PostNL on the basis of the Covenant), and that it did not use the postcode database, so there was no extraction or re-utilization of the whole or of a substantial part of the database.

Second, PostNL contested the termination of the Covenant. According to PostNL, the government's termination of the Covenant was unlawful and it could not terminate the contract in order to evade the prohibition of dissemination for commercial use. The Court stated that the government merely used the possibility for termination foreseen in the Covenant, and had tried to find other solutions, so there was no unlawful termination. However, the Court did find that by already making available the postcodes for commercial use to a software developer before the Covenant had officially ended, the government violated the covenant and should compensate PostNL for its damage.

Third, the Court had to consider whether the government competed unfairly and acted irresponsibly by making the postcode data from the BAG available to third parties. The Court found that there was no unfair competition, because the government acted in accordance with the law on the BAG, with the principles of the PSI directive, and with the principles of the new legislation on market activities of the state (which had not entered into force yet). In addition, the government had given PostNL sufficient notice of its intentions and PostNL's interests were sufficiently protected by the notice period foreseen in the Covenant. Therefore, there was no reason for the government to find the objective of making the data available disproportionate to the negative consequences this would cause.

The government seem to have utilized statutory basis to access the postcode database, while thereafter also entering the market where PostNL was active by giving access to the same PSI bundled with other information under the BAG database for free, on the wholesale and end-user market. 


\subsection{FALKPLAN CASE ${ }^{29}$}

\subsubsection{INTRODUCTION}

In a summary proceedings, the Dutch Court of 's Hertogenbosch refused to impose Falkplan's request for an injunction on the Ministry of Infrastructure and Environment to refrain from making available the national road database for re-use without any conditions, including for commercial purposes. Falkplan, a private company providing route planning and travel information services, claimed that the making available by the Ministry of the road database for re-use would cause irreparable damage to its business model. However, the Court found no sufficiently urgent need to immediately stop the Ministry from disseminating the data. Interestingly, although the Court could have rejected Falkplan's claims on these grounds without any further discussion on the merit of the case, it nevertheless went on to address Falkplan's arguments and found that the Ministries' intentions were fully in line with its obligations under the re-use framework and the (upcoming) changes in the Dutch competition law. Hence, the national road database can be used for any commercial or noncommercial purpose without any restrictions. However, the story is not over yet: in spite of the manifestly clear decision in the summary proceedings, Falkplan has initiated so called 'ground proceedings', which may take up to one year before a decision is rendered (with the possibility of appeal).

\subsubsection{SUMMARY}

In December 2011, in a summary proceedings, the Court of 's Hertogenbosch ruled negatively on the request of Falkplan to restrict the Ministry of Infrastructure and Environment from making the national road database freely available for re-use. This ruling is part of a long dispute between both parties on the possibility for commercial re-use of the national road database. Back in 2006, the Ministry already decided to make this database freely available on the Internet for access and re-use. However,

\footnotetext{
29 - Court decision: http://zoeken.rechtspraak.nl/detailpage.aspx?ljn=BU8010\&u_ljn=BU8010,

- Summary: http://www.rechtspraak.nl/Organisatie/Rechtbanken/Den-

Bosch/Nieuws/Pages...

- Freedom of Information Act:

http://wetten.overheid.nl/BWBR0005252/geldigheidsdatum_15-04-2012,

- Act amending the Competition Act on market activities of the State:

http://www.eerstekamer.nl/9370000/1/j9vvhwtbnzpbzzc/vipgdlr6mked/f=y.pdf,

- Commissie Tweede Consultatieronde Vrijgeven NWB Bestand:

www.rijksoverheid.nl/bestanden/.../advies-cie-tweede-consultatie.pdf
} 
after considerable protest by some private sector mapping companies, an independent commission installed by the Ministry examined the possible impact on the market of releasing the data. This Commission found that there was a public interest that justified opening up the data, based on the national programme for authentic databases and the INSPIRE requirements to make spatial data available (Commissie Tweede Consultatieronde Vrijgeven NWB Bestand 2006). Nevertheless, due to heavy protest of the private sector, the Ministry decided to postpone making the data available for commercial use until 2009, which was later extended to 2011, and only allowed non-commercial use since 2007. This grace period was intended to serve as a transition period for the private sector parties, allowing them to adapt their business model to the new circumstances.

In November 2011, the Ministry decided to make the road database freely available, including for commercial re-use. Falkplan responded by means of a request for a staying order from the Court of 's Hertogenbosch, aiming to prevent the release of the data by the Ministry. The Court refused to impose such a staying order, stating that Falkplan did not show sufficient urgency for an injunction to be granted (under Dutch law, such urgency is a prerequisite for admissibility of parties to summary proceedings). In this context, the Court considered that Falkplan did not provide sufficient evidence of the damage it would incur if commercial re-use of the national road database would be allowed. The mere fact that Falkplan's financial interests were at stake, did not justify an injunction. Secondly, the Court found that Falkplan also failed to show that its existence is endangered by the release of the road database. Falkplan's argument that it had actually calculated the possible losses, but could not release this confidential information because it would harm its position towards its competitors, did not convince the Court. Thirdly, according to the Court, Falkplan also did not have an immediate need for a staying order, because no competitor would be able to offer any competing product within a short term, as the road database would still have to be enriched with many other types of information.

Although the Court could have stopped here, it nevertheless continued by stating that, in case of such lack of urgency, a staying order could only be granted if manifest doubts about the legitimacy of the actions of the Ministry were already clear without any in depth investigation and that in any procedure on the merit of the case the Ministry would also be held in 
the wrong. The Court did not find such manifest doubts, for two main reasons. First, the data held in the road database were collected by the Ministry as part of its public task, and making available the database is part of the Ministry's obligation under the Dutch Freedom of Information Act, which also transposed the PSI directive. Secondly, it referred to the future amendments to the Dutch Competition Act relating to the market activities of the State (and requiring those activities to be charged at full cost), which holds an exception for providing data collected in the course of the public body's public task, essentially allowing public sector bodies to facilitate free commercial re-use of such data.

While there will be a full court procedure on the merit of the case in the future, the Court's refusal to grant a staying order to Falkplan entails that the national road database can be made freely available for any re-use, including for commercial purposes.

\subsection{THREE SWEDISH COMPETITION AUTHORITY CASES}

In three Swedish decisions, the Competition Authority had the opportunity to scrutinize whether PSBs were acting anti-competitive when launching either free searchable databases on their websites, or where the prices on the wholesale level were set to an alleged anti-competitive level compared to the price of access on the end-user market.

\subsubsection{SWEDISH PATENT AND REGISTRATION OFFICE ${ }^{30}$}

In March 2012, the SCA decided in reference to the Trademark register that no further investigation would be made with regard to a possible abuse of a dominant position. The case concerned the fact that the Swedish Patent and Registration Office (SPRO) from 2010 started to offer free access to the Trademark register to the downstream end-user market, whereas customers on the upstream wholesale market are offered more detailed data in different formats (so-called "register lifted data") for a one-time fee and then a yearly fee.

Before 2010, SPRO had offered access to the database to end-users for a fee, and SPRO motivated the decision to eliminate the fee with that free access was within the public task assigned to it by the government. The complaining (incumbent) re-user purported that it was likely it will be squeezed out of the market by SPRO offering a competing product for free.

30 Dnr 470/2011. http://www.kkv.se/Diariet/arende.asp?id=21326\&b=1. Last visited 20140529. 
While the SCA was initiating its investigation, the SPRO announced that it would lower its fees in the wholesale segment in 2013, and the SCA in its decision accepted the lowered fees as reasonable (they would come to corresponded to the marginal costs) and thereby, without dwelling further into the matter, the SCA found that no abuse of dominance was at hand. The SCA concluded, without discussing the requirements, that the SPRO is an undertaking in accordance with the Swedish Competition Act $^{31}$.

\subsubsection{THE SWEDISH METEOROLOGICAL AND HYDROLOGICAL INSTITUTE $^{32}$}

The SCA investigated whether the Swedish Meteorological and Hydrological Institute (SMHI) was in breach of the Swedish Competition Act in a situation similar to the SPRO case above. When SMHI decided to eliminate parts of it fees on the wholesale level and only charge a fee covering the marginal cost of the delivery of large, or cumbersome to collect, data-sets, the SCA closed the investigation. The outcome implied that access, at least on the end-user market, would be granted without any charges.

\subsubsection{THE SWEDISH LAND REGISTRY ${ }^{33}$}

In another case, from November 2012, the SCA assessed the way the Cadastre sells refined information in the land register to commercial private actors. The complaining re-user purported that the Cadastre was not giving access to raw data. Instead, the re-user only got access to refined data, implying that the price was too high, especially in comparison to the fees charged in the end-user market. The SCA did not find any abuse.

The case was decided only weeks after the Compass case, which seems to be the reason why the SCA is not as clear on the issue whether or not the PSB should be considered an undertaking (SCA's "preliminary" assessment wasthat the information supply division of the Cadastre should be considered an undertaking).

In these cases, the SCA and the PSBs actually seem to have taken for granted that the transfer of data to re-users for remuneration in the wholesale market implied that the PSBs were conducting an economic activity and should, thus, be considered undertakings under competition

31 SFS 2008:579. (Swe: Konkurrenslagen)

32 Dnr 800/2011. http://www.kkv.se/Diariet/arende.asp?id=21895\&b=1. Last visited 20140529.

33 Dnr. 601/2011. http://www.kkv.se/Diariet/arende.asp?id=21580\&b=1. Last visited 20140529. 
law. Only in the last case, decided only weeks after Compass, did the SCA start to back-track and relied on the fact that the Swedish Land Registry admitted to the fact that it should be considered an undertaking under Competition law before finding the Registry not abusing its dominant position.

The Swedish PSBs subject to the assessment, referred to the PSI Act in their argumentation. Both the SPRO and the Cadastre seem to have argued upon the assumption that the SCA would at least in some way consider the PSI Act. They argue that their service to supply more detailed information to the upstream markets was a public task, while also the supply for free or to a lesser fee on the end-user market also fell within their public task. Their argumentation indicates that they were possibly concerned that the SCA might indicate that they are re-using their own PSI for commercial purposes, and treating their own commercial branch more favourably than other stakeholders (an Art. 10 (2) situation).

\subsection{ENGLISH CASE}

The Dutch and the Swedish cases above concern with the PSBs giving access to PSI without charges or too less of or no margin compared to the prices at the wholesale level, and thereby frustrated the re-users business models. They argue that by opening up their PSI these governments are conducting unfair competition practices, or at least inflicting damage. The PSBs claimed that giving access for free in the end-market or the wholesale market (or both) is within their public task, and also in line with the spirit of the PSI directive of charging at most marginal cost for accessing the PSI. Stating this there is however other cases were the PSBs are alleged to make use of its prerogative of defining public task so not to give access to PSI, or at least not in the manner, i.e. raw data, requested by the re-users. The Swedish Cadastre case discussed above is one example, another example is the UK Coal Authority Case currently being scrutinized by the UK Courts.

\subsubsection{UK COAL AUTHORITY CASE ${ }^{34}$}

The case relates to a dispute between PinPoint Information Ltd. (PinPoint) and the Coal Authority on the permitted re-use of the Coal Authority's information on coal mining information. The Coal Authority systematically

\footnotetext{
${ }^{34}$ See more at:

http://www.epsiplatform.eu/content/opsi-s-ruling-pinpointinformation\#sthash.D0KcM7RL.dpuf
} 
collects and maintains certain data on past and ongoing coal mining operations. This information is used (among other purposes) in the course of conveyancing: when selling property, information from the Coal Authority is requested in England and Wales though standardized forms (so-called CON29M forms). The reports provided by the Coal Authority in response to these requests (CON29M reports) are then used to determine any risks to the property caused by coal mining activity. Thus, the information is commercially valuable in the course of real estate transactions. Granting access to this PSI is one of the statutory tasks of the Coal Authority.

A number of commercial companies have implemented arrangements with the Coal Authority, under which it supplies CON29M reports for specific properties upon request (for a fee). The commercial companies then use this information to enrich their own data, and sell the results. PinPoint is one such company, which specializes in the commercialization of official geospatial data. PinPoint however sought a more extensive arrangement, seeking to license the entirety of the Coal Authority's databases, rather than obtaining specific information through individual requests on a case-bycase basis. It submitted a request to this effect to the Coal Authority in August 2010. After some discussions PinPoint proposed the establishment of a joint venture with the Coal Authority as a method for implementing this data sharing plan; however, the Coal Authority declined. When PinPoint's request to engage in mediation before the Office of Public Sector Information (OPSI) was refused by the Coal Authority, PinPoint submitted a formal complaint to OPSI.

The complaint related both to the Coal Authority's rejection of the joint venture proposal, and to the failure to grant a licence to re-use the databases as proposed by PinPoint, which PinPoint argues was in violation of the Reuse of Public Sector Information Regulations 2005 (the PSI Regulations).

However, OPSI noted that re-use by definition requires that information is used for a different purpose than the initial purpose within the public task for which the document was produced. Noting that the production of CON29M reports is a part of the Coal Authority's public task, OPSI found that the production of similar reports by private companies is not a form of re-use but rather a replication of existing public tasks, and that the relevant parts of the PSI Regulations therefore did not apply. As PinPoint declined to clarify any further plans for the information (which might have 
gone beyond the production of CON29M equivalent reports, and thus might have constituted re-use covered by the PSI Regulations), OPSI found that the request for re-use did not "state the purpose for which the document is to be re-used", as required under the Regulations.

Ultimately, OPSI decided to partially uphold the complaint. While the complaint could not formally be based on the PSI Regulations due to the fact that PinPoint did not specify any clear intended re-use, OPSI none the less found several deficiencies in the Coal Authority's treatment of the communications. As a result, OPSI recommended that the Coal Authority review its communication to the public, to potential re-users and to OPSI, and that it re-examine the original request.

It is apparent from OPSI's initial complaint findings, that TCA felt to be its public task, to include not just the creation and maintenance of coal risk public records, but also the sale of Con29M coal reports. PinPoint challenged the basis of OPSI's findings and threatened to escalate matters. This resulted, according to anecdotal evidences, in OPSI 'facilitated discussions', which led in turn to an OGL licensing agreement, under which the majority of TCA data was released, and updated for a period of 6 months. During the currency of those discussions and prior to the licensing agreement being in place, TCA published its public task. The scope of its task was extended further to essentially include any use of TCA data in the property market. The case is, also according to anecdotal evidence, on-going in the UK Courts.

\section{ANALYSIS}

The national cases reviewed above are examples of incidents where the Member States prerogative to decide what constitutes public task may have restricting effects on the business activities of the re-users. In the Dutch cases and Swedish Trademark database case, giving access for free and stating that this is within the public task and even promoted under the pricing rules and principles of the PSI directive both limit the business activities of the re-users and encourage them to develop their services. It forces them either to extend and diversify their products so not be seen to be in competition with the service provided for free by the PSBs, or to exit the markets.

In fact the cases above have some differences and similarities. The Dutch PostNL case concerns a PSB entering new markets, with the aim of 
increasing its public tasks in accordance with the national government instructions, by opening up for transferring PSI without charges both in the wholesale and end-users segments. Here the incumbent firm, and the holder of the PSI database, was exposed the competitive pressure from a new entrant being the PSB. The Swedish Trademark case and the Dutch Falkplan case dealt with PSBs starting to give access for free and for commercial re-use, while previously it either charged also end-users or refused giving access for commercial re-use. The PSBs purported that their reason for changing terms of accessing the PSI was to increase availability of PSI under their public tasks, in accordance with the PSI Directive. The UK CAT case is an example of a PSB alleged to have extended the notion public task so to exclude re-users not by giving access but by refusing re-use altogether.

Interestingly, the Swedish re-users in the cases above complained to the SCA regarding the pricing levels of the PSBs under competition law and the abuse of dominance prohibition in an effort to try to limit the impact of the strategies by the PSBs. The SCA relied, and the PSB agreed, that in principle the prohibition of abuse of dominance would have be applicable for the PSBs, save that they had not committed any abuse.

The application of competition law to these cases would also have been beneficial since thereby the PSI directive and the notion of "public task" did not have to be addressed. Competition law could be utilized irrespectively on what the PSBs would be considered to be their public tasks. However, when the last decision was to be handed down by the SCA, the CJEU delivered the Compass case, which seems to restrict the use of competition law when dealing with PSBs and the re-use of PSI. In fact, it seems that the CJEU limits the use of competition law so not to include bodies conducting certain public tasks in reference of collecting and disseminating PSI. The CJEU extended exemption (under the notion of undertaking) for conducts that fall under the 'public power and thereto connected activities' doctrine. It did include also the transfer of PSI between the Austrian state to the agencies, and, perhaps, generally, to the transfer of PSI for re-use if that is within the statutory duties of the PSB.

According to CJEU, data collection activity in relation to undertakings, on the basis of a statutory obligation on those undertakings to disclose the data and powers of enforcement related thereto, falls within the exercise 
of public powers. ${ }^{35}$ As a result, such an activity is not an economic activity. Equally, an activity consisting in the maintenance and making available to the public of the data thus collected, whether by a simple search or by means of the supply of print-outs, in accordance with the applicable national legislation, also does not constitute an economic activity, since the maintenance of a database containing such data and making that data available to the public are activities which cannot be separated from the activity of collection of the data. ${ }^{36}$

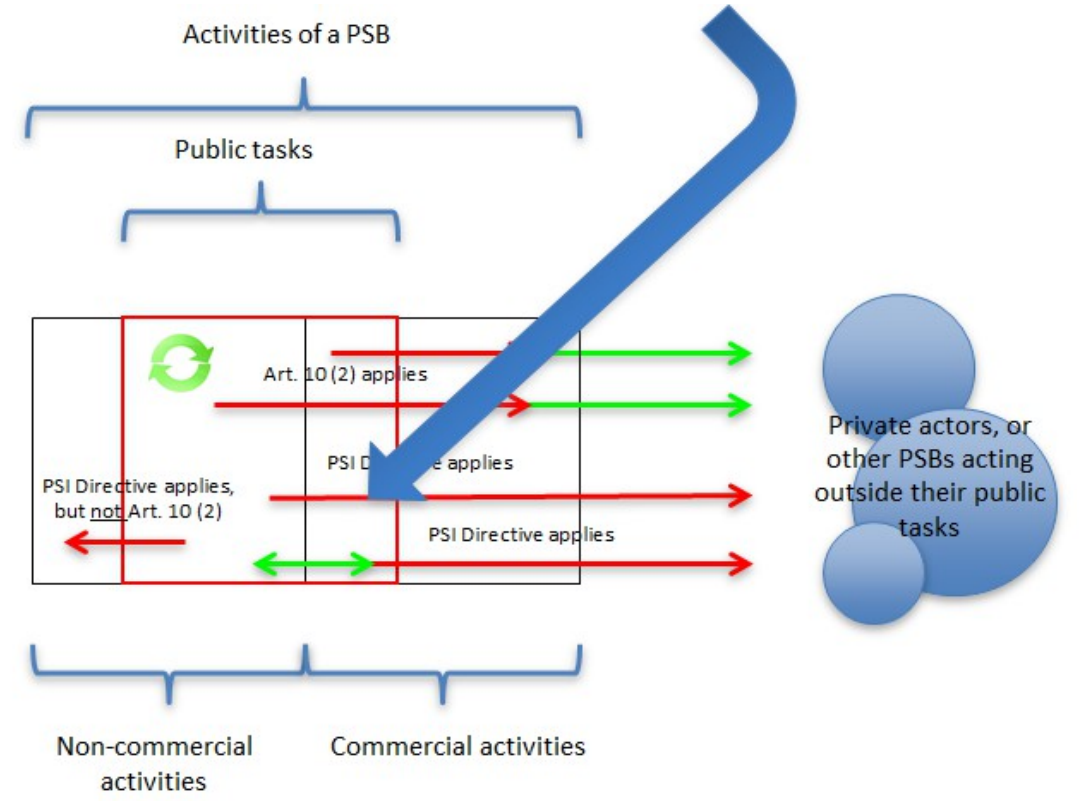

With regard to the fact that the making available to interested persons of the data in such a database is remunerated, the CJEU noted that, in conformity with the case-law, to the extent that the fees or payments due for the making available to the public of such information are not laid down directly or indirectly by the entity concerned but are provided for by law, the charging of such remuneration can be regarded as inseparable from that making available of data. Thus, the charging by Austria of fees or payments due for the making available to the public of that information cannot change the legal classification of that activity, meaning that it does not constitute an economic activity. ${ }^{37}$ It seems that the CJEU thereby address

\footnotetext{
35 Drexl, 2015.

36 Case C-138/11 Compass-databank GmbH v. Republik Österreich 12 July 2012, not yet reported.,para. 41.
} 
the area of public commercial tasks, and finds that competition law not applicable to such conduct.

In light of the Compass case, the national cases reviewed above should perhaps not have been scrutinized under Competition law. The PSBs in those cases all claimed to be active with public tasks in reference with collecting and disseminating PSI under statutory duty. While some of them clearly also are performing public tasks, other forms conduct seem to be both commercial and public tasks. Thus, the Post NL case, where the PSB enters an already existing re-user market by providing PSI for free, seems to imply that anticompetitive exclusionary effects may materialise, while the same conduct also opens up for more re-users to access the PSI and enter downstream markets. There is also the inherent difficulty that the PSBs are giving access for free on already established markets. It creates a strain between competition law principles and that the new PSI Directive actually stipulates that the PSBs as a general rule should price below market price.

\section{POLICY SUGGESTIONS}

Our policy suggestion is based on the finding that we believe that the interface between competition law and PSI directive needs to be clarified. At least, it is not evident when competition law is applicable to PSBs that have as their public task to commercially distribute PSI.

The Commission could try to give guidance on this point in the PSI Licensing Guidelines. However, that may be difficult. An alternative could be that the Commission and, foremost, national competition (or, when applicable PSI) authorities are encouraged to shed some light on the interface by investigating and even litigating such conduct that may be identified as public commercial tasks in the area of PSI. In fact, national competition or PSI authorities could be better placed to do this, while they also could, possibly, scrutinize the important issue of identifying "public tasks". Identifying whether a certain conduct constitutes a "public task" should be done in accordance with the Member States' existing forms of governance and procedure, ${ }^{38}$ and national authorities seem more apt to scrutinize this issue. Similarly, since the Compass case makes a connection between Member States' legislation and the "state action" exemption under

${ }_{37}$ Case C-138/11 Compass-databank GmbH v. Republik Österreich, 12 July 2012, not yet reported.para. 42.

38 Compare Janssen, 2005, 12-13. 
the notion of undertaking, possibly national authorities are better placed to investigate and litigate whether the conduct scrutinized fall under the 'public power and thereto connected activities' doctrine, or whether competition law is applicable.

\section{LIST OF REFERENCES}

Correira, Z.P. 2005, Towards a stakeholder model for the co-production of the public-sector information system, Information Research, vol. 10, no. 3, available at <http://www.informationr.net/ir/10-3/paper228.html>

Drexl, J. 2015, The Competition Dimension of the European Regulation of Public Sector Information and the Concept of an Undertaking in State-Initiated Restraints of Competition, ed. V. Bagnoli and J. Drexl, Edward Elgar, Cheltenham

Janssen, K. 2005, INSIPRE and the PSI Directive: Public Task versus Commercial Activities?, available at:

<http://www.ec-gis.org/Workshops/11ec-gis/papers/303janssen.pdf>

Janssen, K. 2011, What if...? The Magill case redone under the PSI Directive, available at <http://epsiplatform.eu/content/what-if-magill-case-redoneunder-psi-directive>

Lundqvist B., de Vries M., Linklater E. and Malmgren L. R. 2011, Business Activity and Exclusive Right in the Swedish PSI Act, available at <http://www.konkurrensverket.se/globalassets/english/publicationsand-decisions/business-activity-and-exclusive-right-in-the-swedish-psiact.pdf $>$

Lundqvist, B. 2012, Turning Government Data into Gold: The Interface between EU Competition Law and the Public Sector Information Directive - With some Comments on the Compass-Case, IIC, Vol. 44, No. 1, 2013, p. 79-95. 